\title{
Multimodal Diagnostic Imaging for Hyperacute Stroke
}

\author{
(D).D. Vo, (D)A.J. Yoo, (D)A. Gupta, (D). Qiao, (D)A.S. Vagal, (D).A. Hirsch, (DD.M. Yousem, and (D). Lum
}

\begin{abstract}
SUMMARY: In April 2015, the American Roentgen Ray Society and the American Society of Neuroradiology cosponsored a unique program designed to evaluate the state of the art in the imaging work-up of acute stroke. This topic has grown in importance because of the recent randomized controlled trials demonstrating the clear efficacy of endovascular stroke treatment. The authors, who were participants in that symposium, will highlight the points of emphasis in this article.
\end{abstract}

ABBREVIATIONS: NINDS = National Institute of Neurological Disorders and Stroke; ECASS = European Cooperative Acute Stroke Study; MR CLEAN = Multicenter Randomized Clinical Trial of Endovascular Treatment for Acute Ischemic Stroke in the Netherlands; ESCAPE = Endovascular Treatment for Small Core and Anterior Circulation Proximal Occlusion with Emphasis on Minimizing CT to Recanalization Times; EVT = endovascular treatment; EXTEND-IA = Extending the Time for Thrombolysis in Emergency Neurological Deficits-Intra-Arterial; MR RESCUE = Mechanical Retrieval and Recanalization of Stroke Clots Using Embolectomy; SWIFTPRIME = Solitaire With the Intention for Thrombectomy as Primary Endovascular Treatment

$\mathbf{F}^{\circ}$ or $>2$ decades, intravenous tissue plasminogen activator was the only proved therapy for acute ischemic stroke, despite having limited efficacy for large-vessel occlusions and a restrictive timeframe for administration. ${ }^{1,2}$ The recent publication of randomized controlled trials demonstrating a high degree of efficacy for endovascular treatment (EVT) in strokes caused by large-vessel occlusions heralds a new era of acute stroke therapy. The Multicenter Randomized Clinical Trial of Endovascular Treatment for Acute Ischemic Stroke in the Netherlands (MR CLEAN), ${ }^{3}$ Endovascular Treatment for Small Core and Anterior Circulation Proximal Occlusion with Emphasis on Minimizing CT to Recanalization Times (ESCAPE), ${ }^{4}$ Extending the Time for Thrombolysis in Emergency Neurological Deficits-Intra-Arterial (EXTENDIA), ${ }^{5}$ and Solitaire With the Intention for Thrombectomy as Primary Endovascular Treatment (SWIFT-PRIME) ${ }^{6}$ trials dem-

From the Mallinckrodt Institute of Radiology (K.D.V.), Washington University School of Medicine, St. Louis, Missouri; Division of Neurointervention (A.J.Y.), Texas Stroke Institute, Plano, Texas; Department of Radiology and Feil Family Brain and Mind Research Institute (A.G.), Weill Cornell Medical College, New York, New York; Department of Radiology (Y.Q.), Johns Hopkins School of Medicine, Baltimore, Maryland; Department of Radiology (A.S.V.), University of Cincinnati Medical Center, Cincinnati, Ohio; Neurolnterventional Radiology (J.A.H.), Massachusetts General Hospital, Boston, Massachusetts; Department of Radiology (D.M.Y.), Johns Hopkins Medical Institution, Baltimore, Maryland; and Interventional Neuroradiology (C.L.), Ottawa Hospital Research Institute, University of Ottawa, Ottawa, Ontaria, Canada.

Please address correspondence to Katie D. Vo, MD, Mallinckrodt Institute of Radiology, Washington University School of Medicine, 510 South Kingshighway Blvd, Campus Box 8131, St. Louis, MO 63110-1076; e-mail: vok@wustl.edu

- Indicates open access to non-subscribers at www.ajnr.org

Indicates article with supplemental on-line photo.

http://dx.doi.org/10.3174/ajnr.A4530 onstrated that patients with acute ischemic stroke with a proximal large-vessel occlusion of the anterior circulation have significantly improved functional outcomes when EVT is initiated within 6 hours after stroke onset. EVT was used in combination with standard-of-care IV-tPA, resulting in an absolute risk reduction of stroke disability by $14 \%-31 \%$ (the number of patients needed to treat for one patient to have good outcome ranged from 3 to 6 ).

So why did these trials work when other endovascular trials, including the Interventional Management of Stroke-III, ${ }^{7}$ the Mechanical Retrieval and Recanalization of Stroke Clots Using Embolectomy (MR RESCUE), ${ }^{8}$ and the Local Versus Systemic Thrombolysis for Acute Ischemic Stroke trials, had failed? A major contributor to the success of these endovascular trials was superior mechanical thrombectomy devices resulting in safer, faster, and higher rates of reperfusion. Another contributor to the success of these trials seems to have been the use of rapid and accurate imaging screens to select patients with the greatest potential to benefit from the EVT. ${ }^{10,11}$

As treatment for stroke has advanced, the demands for imaging to help select appropriate patients for various treatments have increased. Initially, imaging was used primarily to rule out hemorrhage and stroke mimics. With the more advanced therapeutic options that are currently available, imaging is now used to determine the following: 1) the location of thrombus, 2) the volume of the infarct core, 3) tissue viability, and 4) the degree of collateral circulation. In this portion of the review, we will debate the merits of multimodal CT versus multimodal MR imaging as a tool to identify candidates for intervention, address safety and quality 
Efficacious acute stroke randomized controlled trials

\begin{tabular}{|c|c|c|c|}
\hline Trial & Time Window (hr) & Treatment & Screening Imaging Modality \\
\hline NINDS $^{1}$ & $0-3$ & IV-tPA & NCCT \\
\hline ECASS \|\|$^{2}$ & $3-4.5$ & IV-tPA & $\mathrm{NCCT}$ \\
\hline $\mathrm{TNK}^{25}$ & $0-6$ & IV tenecteplase & $\mathrm{NCCT}+\mathrm{CTA}+\mathrm{CTP}$ \\
\hline MR CLEAN ${ }^{3}$ & $0-6$ & IA thrombectomy & $\mathrm{NCCT}+\mathrm{CTA} / \mathrm{MRA} / \mathrm{DSA}$ \\
\hline ESCAPE $^{4}$ & $0-12$ & IA thrombectomy & NCCT+multiphase CTA \\
\hline EXTEND-IA ${ }^{5}$ & $0-6$ & IA thrombectomy & $\mathrm{NCCT}+\mathrm{CTA}+\mathrm{CTP}$ \\
\hline SWIFT-PRIME ${ }^{6}$ & $0-6$ & IA thrombectomy & $\mathrm{NCCT}+\mathrm{CTA} / \mathrm{MRA} \pm \mathrm{CTP} / \mathrm{MRP}$ \\
\hline
\end{tabular}

Note:-NINDS indicates National Institute of Neurological Disorders and Stroke; ECASS, European Cooperative Acute Stroke Study; TNK, tenecteplase; MR CLEAN, Multicenter Randomized Clinical Trial of Endovascular Treatment for Acute Ischemic Stroke in the Netherlands; IA, intra-arterial; MRP, MR perfusion.

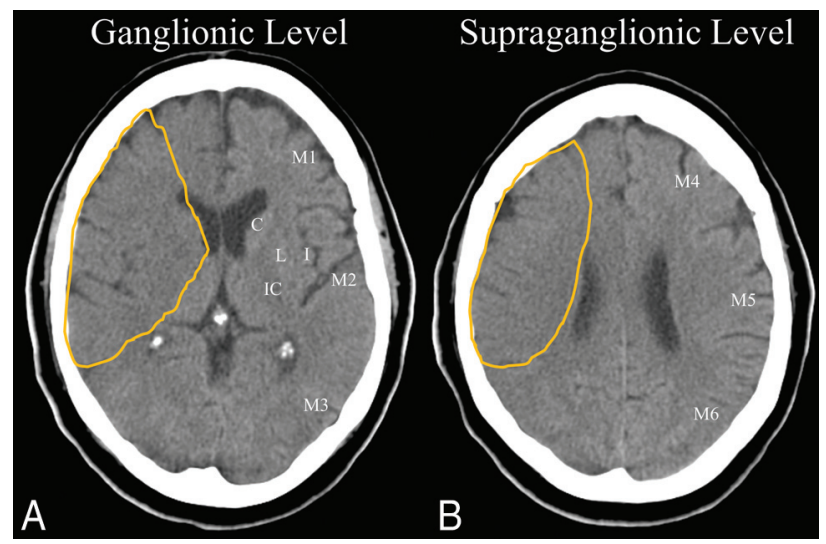

FIGURE. ASPECTS ${ }^{21}$ scoring on an NCCT of a 52-year-old woman 2.5 hours after the onset of a left hemiparesis. Ten defined regions of the MCA distribution are identified on a normal left cerebral hemisphere at ganglionic $(A)$ and supraganglionic $(B)$ levels: the caudate nucleus (C), the lentiform nucleus (L), the internal capsule (IC), the insular cortex (I), and M1, M2, M3, M4, M5, and M6. The outlined areas in the right hemisphere show hypoattenuation in 8 regions given an ASPECTS score of 2.

issues in stroke imaging, and highlight key aspects of vessel wall imaging.

\section{Multimodal CT as an Effective Screening Tool for Acute Stroke Treatment}

A review of each of the positive randomized controlled trials for acute ischemic stroke treatment revealed that CT was the imaging technique of choice to select patients for treatment (Table). Only a few randomized controlled trials, Echo planar Imaging Thrombolytic Evaluation trial, ${ }^{12}$ Study of Desmoteplase In Acute Ischemic Stroke phase II, ${ }^{13}$ and MR RESCUE, ${ }^{8}$ used MR imaging as a screening tool (some also permitted CTP); but none of these trials demonstrated efficacy. Multimodal CT, including NCCT, CTP, and CTA, is capable of addressing all the acute imaging needs required for screening thrombectomy candidates: ruling out hemorrhage and identifying large-vessel occlusion, detecting infarct core and penumbra, and assessing collateral flow. Most important, in most settings, accessibility to CT is fast and efficient.

Rule Out Hemorrhage. NCCT is widely accepted as the criterion standard for imaging intracerebral hemorrhage and can reliably identify acute hemorrhage with high sensitivity. Despite the heightened sensitivity of SWI to microbleeds, several studies suggest that neither the presence nor the number of cerebral microbleeds is associated with a significantly increased risk of hemorrhagic transformation in tPA-treated or untreated patients. ${ }^{14-16}$
One study showed a higher risk of symptomatic hemorrhage after intravenous thrombolysis in patients with $>5$ microbleeds but no association with less favorable outcome. ${ }^{17}$ More studies to assess the safety and effectiveness of thrombolysis in patients with microbleeds are needed.

Detection of Large-Vessel Occlusion. Vascular imaging was required in all 4 of the positive endovascular trials. CTA was the imaging technique of choice in the 4 randomized controlled trials for thrombectomy. ${ }^{18}$ CTA can be performed immediately following NCCT. It is fast, less prone to motion, and widely available in the community. It is safe and can be performed without first screening for renal function (discussed below). The only contraindication to CTA is a severe contrast allergy, in which case MRA can be performed but will potentially delay time-sensitive therapies by $18-30$ minutes. ${ }^{19,20}$

Detection of Core and Penumbra. Patients with a large infarct core are unlikely to benefit from endovascular therapy. One surrogate measure for the extent of the core is the semiquantitative Alberta Stroke Program Early CT Score (Figure), which quantifies early ischemic changes in the middle cerebral artery territory on NCCT. ${ }^{21}$ This 10 -point scoring system systematically rates early signs of ischemia in defined brain regions; a score of 10 indicates a scan with normal findings, and 1 point is subtracted for each abnormal brain region. A score of $<4$ is considered significant, indicating a large infarct core, and is associated with increased risk of hemorrhagic transformation and poor outcomes after thrombolysis. $^{22}$ Because of these associations, patients with an ASPECTS of $<6$ were excluded from enrollment in 3 of the 4 positive thrombectomy trials. ${ }^{4-6}$

The ischemic penumbra, defined as brain tissue that will die if untreated but survive if reperfused, can be assessed with either MR perfusion or CTP. There are strong advocates for using CTP to select patients for endovascular therapy, though a growing number think that CTP is inappropriate in an individual patient, arguing that the error bars associated with the noisy postprocessing algorithms are large. ${ }^{23,24}$ CTP was used in 3 positive randomized controlled trials of endovascular therapy (ESCAPE, ${ }^{4}$ EXTEND-IA, ${ }^{5}$ and SWIFT-PRIME ${ }^{6}$ ) and a trial using IV tenecteplase ${ }^{25}$ (genetically modified tissue plasminogen activator), to identify the penumbra before inclusion in the trials. These outcomes do not establish the necessity of CTP for identifying patients who will benefit from reperfusion therapy because numerous trials that did not use perfusion imaging still demonstrated efficacy.

Detection of Collateral Flow. Multiphase CTA is a new technique that allows a quick visual assessment of collateral flow in the affected territory. ${ }^{26}$ The technique requires 3 scans after a contrast bolus to capture the arterial, midvenous, and late venous phases. The degree of enhancement of pial arteries distal to the occlusion positively correlates with the degree of collaterals (On-line Figure). In the setting of a proximal large-vessel occlusion, the presence of good collateral vessels is more likely to be associated with a smaller core and more salvageable brain tissue and has been shown to be a strong predictor of good outcomes. Patients with 
poor collaterals were excluded from the ESCAPE and SWIFT PRIME trials, to help refine patient selection. The challenge of using collateral-based selection is the following: the nonstandardized approach to collateral grading and the dependence of the technique on noninvasive evaluation. ${ }^{27}$

CT has the advantage of having a rapid and efficient workflow (see discussion below). "Time is brain" is an important concept that stems from meta-analyses of IV-tPA trials demonstrating that the number of patients needed to be treated for 1 good outcome increases from 5 to 9 to 15 patients with every 90 -minute delay in treatment. ${ }^{28} \mathrm{~A}$ similar inverse relationship is seen between outcome and time to reperfusion for endovascular interventions. ${ }^{29}$ The total scan time for a multimodal CT is approximately 5 minutes, while rapid MR imaging protocols can be reduced to 10-15 minutes. Although the difference in actual imaging time between CT and MR imaging is small, a number of additional hurdles can add significantly to MR imaging times: the availability of a scanner, screening for MR imaging safety, transporting patients to the scanner often outside the emergency department, transferring patients in and out of the scanner with MR imaging-compatible equipment, positioning the patient, and so forth. These delays of 18-30 minutes may seem small, but when considering an emergency department arrival to groin puncture times of 95 minutes, the delays are significant. ${ }^{19,20}$ In addition to delays, MR imaging is contraindicated in up to $20 \%$ of patients with acute stroke due to patient-related factors such as cardiac pacemakers and medical instability. ${ }^{30}$

In summary, MR imaging may be equivalent or superior to CT in its ability to address all imaging goals for acute ischemic stroke. However, obstacles for its use in the acute setting of stroke may limit its utility, though these obstacles may be overcome with workflow optimization. CT is faster and, some argue, able to satisfy the various imaging requirements for current time-sensitive therapeutics in a wider population. Most important, it is the most consistently used imaging technique in the trials of acute ischemic stroke treatments that were shown to be efficacious.

\section{Multimodal MR Imaging as an Effective Screening Tool for Acute Stroke Treatment}

All of the recent positive trials used CT for imaging selection. As such, no class I clinical evidence supports patient evaluation by using MR imaging. However, this lack of evidence does not signify the superiority of CT, just its greater feasibility in current clinical practice. Strong evidence supports the use of MR imaging to improve the safety profile and cost-effectiveness of intra-arterial treatment, which relies primarily on the greater accuracy of DWI to depict acute brain infarction. Using a streamlined protocol, MR imaging can provide all the necessary information for treatment decision-making and can be performed without a significant time delay. ${ }^{31}$

Rule Out Hemorrhage. Gradient recalled-echo T2*-weighted imaging and SWI are highly sensitive to blood-breakdown products. In acute stroke, gradient recalled-echo $\mathrm{T} 2^{\star} \mathrm{WI}$ has been shown to be as accurate as NCCT for the detection of acute intracranial hemorrhage and is superior to CT in the detection of chronic hemorrhage. ${ }^{32}$ Within 6 hours of stroke onset (ie, treatment window for reperfusion), 1 study found a $96 \%$ concordance between CT and MR imaging for acute intracranial hemorrhage, ${ }^{32}$ while another study reported a $100 \%$ accuracy of MR imaging for detecting intracerebral hemorrhage by using experienced readers and NCCT as the reference standard. ${ }^{33}$ On the basis of these results, MR imaging is an excellent technique for distinguishing ischemic and hemorrhagic stroke for consideration of reperfusion therapy and is supported by recent American Heart Association guidelines (class I, level of evidence A). ${ }^{34}$

Documenting Proximal Artery Occlusion. Occlusive thrombus in the proximal intracranial arteries is the target of intra-arterial therapy. Therefore, noninvasive vessel imaging is critical for the rational delivery of this treatment (American Heart Association class I, level of evidence A). ${ }^{34}$ Moreover, it provides important pretreatment data for the neurointerventionalist, who can choose the appropriate access tools in the case of arterial tortuosity or when treatment is required for steno-occlusive disease at the carotid bifurcation.

Although CTA provides the best noninvasive evaluation of the intracranial vessels, ${ }^{35}$ MRA appears sufficient for decision-making regarding intra-arterial therapy. 3D TOF MRA has been shown to have $84 \%-87 \%$ sensitivity and $85 \%-98 \%$ specificity for identifying proximal artery occlusion. ${ }^{18,36}$ Contrast-enhanced MRA offers faster acquisition times, wider coverage, and less flowrelated signal loss but has lower spatial resolution and venous contamination. ${ }^{37}$ Both CTA and MRA are recommended for noninvasive vessel imaging during acute stroke evaluation by American Heart Association guidelines (class I, level of evidence A). ${ }^{34}$

Identifying Large Infarcts for Treatment Exclusion. It is biologically intuitive that patients with large infarcts will do poorly irrespective of treatment. Although thresholds that define what is too large for treatment vary depending on the clinical setting (eg, age, outcomes of interest), it is generally accepted that infarct volumes of $>70-100 \mathrm{~mL}$ are highly predictive of poor outcome. ${ }^{38,39}$ This volume approximates one-third of the MCA territory, but quantification (eg, by using the $\mathrm{ABC} / 2$ ellipsoid approximation) improves the precision over the traditional method of gross visual estimation. Moreover, such infarcts appear to be at higher risk for treatment-related complications, namely reperfusion hemorrhage. ${ }^{38,40}$ For these reasons, it is important to have an accurate and reliable method for determining infarct volume in the treatment window.

Currently, DWI is the best clinically available technique to depict hyperacute infarction (American Heart Association class I, level of evidence A). ${ }^{41,42}$ It has a reported $91 \%-100 \%$ sensitivity and $86 \%-100 \%$ specificity for infarct detection within the first 6 hours, as well as excellent interrater reliability. ${ }^{43,44}$ Moreover, given the superior tissue contrast, it allows volumetric quantification. Despite early reports of diffusion lesion reversal, subsequent studies have shown that true reversal is rare and not clinically significant. ${ }^{45}$ Even with near-complete (>90\%) reperfusion, the rate of significant diffusion lesion volume reversal was $<5 \% .{ }^{46}$ In comparison, all the CT-based techniques have major limitations. Like CTP, CTA source imaging is limited by technique, and hypoattenuated lesion volume has been shown to vary depending on when the brain is imaged during contrast transit. ${ }^{47}$ The most reliable CT sign of early infarction is tissue hypoattenuation on 
NCCT, which reflects a net increase in tissue water. This sign demonstrates limited sensitivity $(\sim 70 \%)$ but is highly specific (100\%) for infarction. ${ }^{48}$

Two recent studies have shown the superiority of DWI over NCCT for evaluating patients who undergo EVT. The first was a post hoc analysis of patients receiving EVT in the Diffusion Weighted Imaging Evaluation for Understanding Stroke Evolution Study 2 who had pretreatment MR imaging and NCCT. The investigators found that ASPECTS graded on DWI had superior interrater agreement (intraclass correlation coefficient, 0.87 versus 0.58 ) and predicted 90-day good outcome better (C statistic, 0.71 versus $0.55 ; P=.03$ ) than NCCT ASPECTS. ${ }^{49}$ The second study was a single-center cohort analysis in which 2 separate imaging-selection approaches were compared. ${ }^{50}$ In the first cohort, patients with proximal artery occlusions were evaluated for intraarterial therapy by using NCCT and CTA, and in a subsequent cohort, DWI was performed in addition to NCCT and CTA. Most important, in both cohorts, the investigators analyzed outcomes in patients who were both treated and excluded from treatment and found that the cohort in which DWI was performed had better 30-day good outcomes (mRS $0-2: 23.6 \%$ versus $9.1 \%$ ), lower mortality (25\% versus $48.5 \%$ ), and lower symptomatic hemorrhage rates (3.9\% versus $10.2 \%$ ), despite fewer patients being treated endovascularly (51.7\% versus $96.6 \%)$. This finding suggests that MR imaging is appropriately excluding patients who are being harmed by intra-arterial therapy, namely those with large infarcts, and it equates to more cost-effective treatment delivery. Taken together, these studies support the promise of improved patient selection by using MR imaging.

\section{Quality and Safety in Stroke Imaging}

Imaging in the Stroke Workflow. As we integrate the evidence from the newer trials into our stroke workflow, time is critical. The national quality-improvement initiative of the American Heart Association and American Stroke Association to improve care in acute stroke, termed "Target: Stroke," highlights best practice strategies to reduce treatment times. ${ }^{51}$ Urging rapid acquisition and interpretation of brain imaging, the authors recommend that $80 \%$ of patients with acute stroke evaluated for revascularization should have NCCT or MR imaging within 25 minutes, and $80 \%$ of patients should have interpretations within 45 minutes of arrival. ${ }^{52}$

Given the overwhelmingly positive results of the randomized controlled trials, there will be a shift toward increased use of advanced imaging in acute stroke. However, the randomized controlled trials also emphasized faster door-to-reperfusion times. In fact, the stroke workflow needs to run in a parallel fashion rather than being a linear process. ${ }^{53,54}$ IV-tPA could be administered in the imaging suite as soon as the NCCT excludes hemorrhage, while CTA/CTP imaging is simultaneously being performed. ${ }^{55}$ The stroke imaging protocols need to be modeled after trauma, necessitating the same level of urgency, targeting all points of delay: stroke-alert notification to radiologists, point-of-care testing, forgo blood work to verify creatinine levels, separation of reads of NCCT from multimodal imaging (CTA/CTP), rapid automated postprocessing of perfusion when performed, and con- vergence of teams to CT/MR imaging, where management decisions are made. ${ }^{55}$

MR imaging protocols usually have longer acquisition times and limited availability compared with CT, taking up to 15-20 minutes. ${ }^{56}$ A faster 6-minute multimodal MR imaging protocol for acute stroke by using a combination of echo-planar and parallel acquisition has recently been published. ${ }^{31}$ Centers that routinely use MR imaging-based paradigms for stroke need to design efficient process flows, including the availability of MR imaging in the emergency department, rapid safety screening (from charts, patients, family, and examination for scars), point-of-care creatinine level evaluation to minimize the risk for gadolinium-induced nephrogenic systemic fibrosis, and efficient stroke protocols.

In addition, one must optimize data collection to drive system improvement, ${ }^{57}$ including time intervals and clinical outcomes, into a database, trial, or registry such as Get With The Guidelines Stroke Patient Management Tool (http://www.heart.org/HEARTORG/ HealthcareResearch/GetWithTheGuidelines/GetWithThe Guidelines-Stroke/Get-With-The-Guidelines-Stroke-PatientManagement-Tool_UCM_308035_Article.jsp). Standardized and comprehensive data collection can be a powerful tool in providing feedback and bench marking to national averages and eventually changing outcomes.

Radiation Safety. It has been well-publicized in the media that $>200$ patients undergoing CTP in 1 center were exposed to $>8$ times the normal radiation dose, resulting in bandlike alopecia. One reason cited was an unrecognized alteration in the scanning protocols that did not diminish image quality and thus went undetected. $^{58}$

Dose-length product is routinely used to estimate dose per patient. This can be converted to millisieverts as a measurement of "effective dose." The typical millisievert exposure for a total stroke imaging NCCT, CTA, and CTP is approximately 9-10 $\mathrm{mSv}$. If one puts that into perspective, a head CT with and without contrast is estimated to have an effective dose of $4 \mathrm{mSv}$, equivalent to approximately 16 months' background radiation. ${ }^{59}$ Some centers without CTP are using multiphase CTA, which incurs an incremental $1 \mathrm{mSv}$ of exposure. ${ }^{26}$

Dose is dependent on tube current (milliampere-second), kilovolt peak, pitch, and collimation. The most frequent method used to limit dose is to reduce the milliampere-second; however, this reduction increases image noise. Image noise may be partially compensated by postprocessing techniques such as iterative reconstruction without incurring a dose penalty. Iterative reconstruction leads to a qualitative smoothing of image edges. Reducing kilovolt peak is a well-accepted strategy as long as it is not met with an automatic increase in milliampere-second to compensate for image quality. Currently, 80 kilovolt peak is the standard for $\mathrm{CTP}$, with some newer research exploring the dose benefits of 70 kilovolt peak. ${ }^{60}$ Another method of potentially reducing exposure is increasing the sampling interval for CTP examinations without significantly impacting image quality. ${ }^{61}$ Therefore, awareness of the dose parameters affecting imaging quality is imperative. Add to the CT dosage the new recommendations for fluoroscopically guided EVT, and radiation exposure in a young patient with stroke may become a safety consideration.

AJNR Am J Neuroradiol 36:2206-13 Dec 2015 www.ajnr.org 
Contrast Safety. The overall risk of contrast-induced nephropathy is approximately $2 \%-5 \%$ for patients with a glomerular filtration rate of 15-40 and higher for patients with a glomerular filtration rate of $<15 .{ }^{62}$ Multiple studies have demonstrated that administration of a contrast-enhanced protocol involving CTA/ CTP and DSA in select patients does not appear to increase the incidence of contrast-induced nephropathy. ${ }^{63,64}$ The risk of contrast-induced nephropathy is overestimated, and a significant proportion of transient creatinine elevation is due to expected fluctuation and underlying disease ${ }^{65}$ Hence the concern regarding the need to verify renal function before administering iodinated contrast in the acute stroke setting is overstated. Nephrogenic systemic fibrosis has been virtually eliminated by restricting gadolinium usage to patients with glomerular filtration rates of $>30$. $^{66}$

Endovascular Treatment Center Availability. Historically, it has been difficult to estimate the number of patients treated with EVT. ${ }^{67,68}$ Increasing demands for EVT will be accompanied by a commensurate change in the workload for existing regional and comprehensive stroke centers. Currently, it is estimated that adequate staffing is available to roughly $95 \%$ of the US population. ${ }^{69}$ However, the recent trials have set lofty targets for revascularization times. In ESCAPE, the median time from stroke onset to CT imaging was 134 minutes and an imaging to groin puncture was 51 minutes, resulting in an onset-to-reperfusion time of just $>4$ hours (241 minutes). In SWIFT PRIME, the median time from arrival in the emergency department to groin puncture was 90 minutes, and from qualifying image to groin puncture, it was 57 minutes. Achieving these targets will be challenging in regions where geography limits accessibility to centers with neurointerventional expertise.

\section{The Future of Hyperacute Stroke Imaging: Emphasis on Large Vessels?}

With the recent excitement over the success of EVT, there will no doubt be increasing demands on acute multimodal diagnostic imaging to further guide therapeutic decision-making to enhance efficacy. In particular, large vessels may need further characterization to assess the benefits and risks tailored to specific acute therapies or for subsequent management decisions. Many studies have focused on direct cranial intravascular thrombus imaging by using NCCT or MR imaging to predict recanalization efficacy with EVT. Because a large thrombus burden is associated with lower rates of recanalization with $\mathrm{EVT},{ }^{70}$ reconstructed thin-section NCCT $(0.625-1.25 \mathrm{~mm})$ has been used to improve the sensitivity of clot detection and the accuracy of clot quantification in the middle cerebral artery. ${ }^{71,72}$ In addition, unlike pharmacologic fibrinolysis, recanalization rates by using mechanical thrombectomy are influenced more by the morphology of the target thrombus than its volume. One study showed that the recanalization rate is 3 times more common with a straight unbranched thrombus than with a branched tortuous thrombus as measured on gradient recalled-echo T2* WI by using the Merci device (Concentric Medical, Mountain View, California) for thrombectomy. ${ }^{73}$ This outcome is primarily due to the mechanical force dispersion with a different shape of the clot during the retrieval. Thus, imag- ing characteristics of the thrombus may help in choosing the best EVT for successful recanalization.

Although past vascular imaging effort was largely focused on extracranial vessel imaging, some of the same principles may apply to large proximal intracranial vessels. This research will have greater application for intracranial atherosclerotic disease and its treatment than for embolic occlusions, which account for most conditions of patients undergoing thrombectomy.

MR vessel wall imaging is a powerful tool for extracranial (eg, carotid) plaque characterization, enabling the determination of stroke risk from carotid plaque rupture. ${ }^{74}$ Recently, this technique has been implemented in several population-based studies to determine the plaque component prevalence and the associated risk that leads to stroke. ${ }^{75}$ Both the Atherosclerosis Risk in Communities study ${ }^{76}$ and the Multi-Ethnic Study of Atherosclerosis ${ }^{77}$ have shown that the extent of carotid plaque and lipid core presence measured on MR imaging is associated with blood cholesterol levels. However, very few epidemiologic MR imaging studies have reached adequate numbers of outcomes (stroke events) since the initial MR imaging study. The Multi-Ethnic Study of Atherosclerosis carotid MR imaging study first reported associations of carotid plaque features with future events. ${ }^{78}$ It showed that the remodeling index and lipid core presence measured on MR imaging added a risk for a new event beyond traditional risk factors in individuals without a history of cardiovascular disease. Future population-based studies to explore the predictive value of other high-risk plaque elements (eg, intraplaque hemorrhage or fibrous cap thinning/rupture) could provide insight in identifying asymptomatic individuals at risk for events. This insight will allow us to define a subgroup of asymptomatic patients who may benefit from therapeutic strategies that can target such vulnerable features.

Compared with extracranial atherosclerosis, intracranial atherosclerosis has been much less commonly studied in epidemiologic research due to the lack of an appropriate diagnostic tool to depict the intracranial vessel wall. Recent developments in 3D vessel wall MR imaging enable screening of major intracranial atherosclerosis $^{79,80}$ and provides reliable wall measurements in a population-based study (Atherosclerosis Risk in CommunitiesNeurocognitive study ${ }^{81}$ ). The prevalence of intracranial atherosclerosis in the Atherosclerosis Risk in Communities population (mean age, 77.1 years) was $34.4 \%$ and higher in African Americans compared with whites. ${ }^{81}$ Future prospective epidemiologic studies that examine intracranial plaque burden in relation to risk factors and vascular markers (contemporaneous and change from earlier baseline measures) would contribute to a more comprehensive understanding of stroke risk.

Vessel wall imaging techniques have emerged to complement luminal stenosis assessments by providing a more detailed evaluation of intracranial vasculopathies. For example, recent studies suggest that multisequence, high-resolution MR wall imaging may differentiate atherosclerosis from other causes of vessel narrowing, such vasculitis, ${ }^{82}$ and might aid in determining the etiology after acute ischemic stroke, given that culprit atherosclerotic lesions may preferentially demonstrate wall enhancement. ${ }^{83}$ Larger, prospective studies with vessel wall imaging techniques are warranted to examine whether such methods could play a 
more routine role in stroke prevention and diagnosis in patients with large-vessel atherosclerotic disease.

\section{CONCLUSIONS}

As we enter this new era of acute stroke therapeutics, our reliance on rapid diagnostic imaging to help guide therapy will continue to increase. The goal of imaging is to enhance the therapeutic index of available treatment options by selecting patients who have the greatest potential to benefit. Vital to the efficacy of any acute stroke treatment is time; therefore, diagnostic tests must be fast, reliable, and operationally efficient. Current treatment algorithms favor multimodal CT imaging even though MR imaging may be superior in individual diagnostic tasks. MR imaging shows promise in providing signatures for penumbra and core and may one day provide information beyond anatomic large-vessel occlusion to help guide advanced endovascular approaches as our therapeutic and diagnostic technology evolves.

Disclosures: Albert J. Yoo-UNRELATED: Consultancy: Neuravi*; Grants/Grants Pending: Penumbra, ${ }^{*}$ Neuravi, ${ }^{*}$ Comments: core imaging lab. Ajay GuptaUNRELATED: Grants/Grants Pending: Foundation of the American Society of Neuroradiology Scholar Award, ${ }^{*}$ National Institutes of Health/National Center for Advancing Translational Sciences Grant No. ULITR00457, * Comments: grants supporting research related to imaging of stroke and cerebrovascular disease. Ye QiaoUNRELATED: Grants/Grants Pending: NIH K99HL106232 and R00HL106232. Comments: MRI imaging of intracranial atherosclerosis. Achala S. Vagal—UNRELATED: Grants/Grants Pending: Clinical and Translational Science Awards 8 UL1 TR000077-05 KL2 research award, * Genentech (research grant). * Joshua A. HirschUNRELATED: Consultancy: Medtronic, CareFusion, Comments: Medtronic, interventional spine, ongoing; CareFusion, single episode in time; taught a spine-related course; Stock/Stock Options: Intratech, InNeuroCo, Comments: Intratech, development-stage stroke company; InNeuroCo, development-stage catheter company. David M. Yousem—UNRELATED: Expert Testimony: Medicolegal consultations; Payment for Lectures (including service on Speakers Bureaus): American College of Radiology Education Center*; Royalties: Elsevier; Payment for Development of Educational Presentations: CMElnfo.com for Hopkins Continuing Medical Education courses. * *oney paid to the institution.

\section{REFERENCES}

1. National Institute of Neurological Disorders and Stroke rt-PA Stroke Study Group. Tissue plasminogen activator for acute ischemic stroke. N Engl J Med 1995;333:1581-87 CrossRef Medline

2. Hacke W, Kaste M, Bluhmki E, et al; ECASS Investigators. Thrombolysis with alteplase 3 to 4.5 hours after acute ischemic stroke. N Engl J Med 2008;359:1317-29 CrossRef Medline

3. Berkhemer OA, Fransen PS, Beumer D, et al; MR CLEAN Investigators. A randomized trial of intraarterial treatment for acute ischemic stroke. N Engl J Med 2015;372:11-20 CrossRef Medline

4. Goyal M, Demchuk AM, Menon BK, et al; ESCAPE Trial Investigators. Randomized assessment of rapid endovascular treatment of ischemic stroke. N Engl J Med 2015;372:1019-30 CrossRef Medline

5. Campbell BC, Mitchell PJ, Kleinig TJ, et al; EXTEND-IA Investigators. Endovascular therapy for ischemic stroke with perfusion-imaging selection. N Engl J Med 2015;372:1009-18 CrossRef Medline

6. Saver JL, Goyal M, Bonafe A, et al; SWIFT PRIME Investigators. Stent-retriever thrombectomy after intravenous t-PA vs. t-PA alone in stroke. N Engl J Med 2015;372:2285-95 CrossRef Medline

7. Broderick JP, Palesch YY, Demchuk AM, et al; Interventional Management of Stroke (IMS) III Investigators. Endovascular therapy after intravenous t-PA versus t-PA alone for stroke. $N$ Engl J Med 2013;368:893-903 CrossRef Medline

8. Kidwell CS, Jahan R, Gornbein J, et al; MR RESCUE Investigators. A trial of imaging selection and endovascular treatment for ischemic stroke. N Engl J Med 2013;368:914-23 CrossRef Medline

9. Ciccone A, Valvassori L, Nichelatti M, et al; SYNTHESIS Expansion
Investigators. Endovascular treatment for acute ischemic stroke. N Engl J Med 2013;368:904-13 CrossRef Medline

10. Albuquerque FC, Fiorella D, Hirsch JA, et al. The tribulations of stroke trials. J Neurointerv Surg 2013;5:181-83 CrossRef Medline

11. Fiorella D, Hirsch JA, Mocco J. In search of the optimized stroke trial design. J Neurointerv Surg 2014;6:249-51 CrossRef Medline

12. Davis SM, Donnan GA, Parsons MW, et al; EPITHET investigators. Effects of alteplase beyond $3 \mathrm{~h}$ after stroke in the Echoplanar Imaging Thrombolytic Evaluation Trial (EPITHET): a placebo-controlled randomised trial. Lancet Neurol 2008;7:299-309 CrossRef Medline

13. Hacke W, Furlan AJ, Al-Rawi Y, et al. Intravenous desmoteplase in patients with acute ischaemic stroke selected by MRI perfusiondiffusion weighted imaging or perfusion CT (DIAS-2): a prospective, randomised, double-blind, placebo-controlled study. Lancet Neurol 2009;8:141-50 CrossRef Medline

14. Fiehler J, Albers GW, Boulanger JM, et al; MR STROKE Group. Bleeding risk analysis in stroke imaging before thrombolysis (BRASIL): pooled analysis of $\mathrm{T} 2{ }^{\star}$-weighted magnetic resonance imaging data from $\mathbf{5 7 0}$ patients. Stroke 2007;38:2738-44 CrossRef Medline

15. Lee SH, Kang BS, Kim N, et al. Does microbleed predict haemorrhagic transformation after acute atherothrombotic or cardioembolic stroke? J Neurol Neurosurg Psychiatry 2008;79:913-16 CrossRef Medline

16. Kakuda W, Thijs VN, Lansberg MG, et al; DEFUSE Investigators. Clinical importance of microbleeds in patients receiving IV thrombolysis. Neurology 2005;65:1175-78 CrossRef Medline

17. Dannenberg S, Scheitz JF, Rozanski M, et al. Number of cerebral microbleeds and risk of intracerebral hemorrhage after intravenous thrombolysis. Stroke 2014;45:2900-05 CrossRef Medline

18. Bash S, Villablanca JP, Jahan R, et al. Intracranial vascular stenosis and occlusive disease: evaluation with CT angiography, MR angiography, and digital subtraction angiography. AJNR Am J Neuroradiol 2005;26:1012-21 Medline

19. Menon BK, Almekhlafi MA, Pereira VM, et al; STAR Study Investigators. Optimal workflow and process-based performance measures for endovascular therapy in acute ischemic stroke: analysis of the Solitaire FR thrombectomy for acute revascularization study. Stroke 2014;45:2024-29 CrossRef Medline

20. Sheth KN, Terry JB, Nogueira RG, et al. Advanced modality imaging evaluation in acute ischemic stroke may lead to delayed endovascular reperfusion therapy without improvement in clinical outcomes. J Neurointerv Surg 2013;5(suppl 1):i62-65 CrossRef Medline

21. Pexman JH, Barber PA, Hill MD, et al. Use of the Alberta Stroke Program Early CT Score (ASPECTS) for assessing CT scans in patients with acute stroke. AJNR Am J Neuroradiol 2001;22:1534-42 Medline

22. Yoo AJ, Zaidat OO, Chaudhry ZA, et al; Penumbra Pivotal and Penumbra Imaging Collaborative Study (PICS) Investigators. Impact of pretreatment noncontrast CT Alberta Stroke Program Early CT Score on clinical outcome after intra-arterial stroke therapy. Stroke 2014;45:746-51 CrossRef Medline

23. González RG. Low signal, high noise and large uncertainty make CT perfusion unsuitable for acute ischemic stroke patient selection for endovascular therapy. J Neurointerv Surg 2012;4:242-45 CrossRef Medline

24. González RG, Copen WA, Schaefer PW, et al. The Massachusetts General Hospital acute stroke imaging algorithm: an experience and evidence based approach. J Neurointerv Surg 2013;5(suppl 1): i7-12 CrossRef Medline

25. Parsons M, Spratt N, Bivard A, et al. A randomized trial of tenecteplase versus alteplase for acute ischemic stroke. NEngl J Med 2012; 366:1099-107 CrossRef Medline

26. Menon BK, d'Esterre CD, Qazi EM, et al. Multiphase CT angiography: a new tool for the imaging triage of patients with acute ischemic stroke. Radiology 2015;275:510-20 CrossRef Medline 27. McVerry F, Liebeskind DS, Muir KW. Systematic review of methods 
for assessing leptomeningeal collateral flow. AJNR Am J Neuroradiol 2012;33:576-82 CrossRef Medline

28. Lees KR, Bluhmki E, von Kummer R, et al. Time to treatment with intravenous alteplase and outcome in stroke: an updated pooled analysis of ECASS, ATLANTIS, NINDS, and EPITHET trials. Lancet 2010;375:1695-703 CrossRef Medline

29. Khatri $P$, Yeatts SD, Mazighi M, et al. Time to angiographic reperfusion and clinical outcome after acute ischaemic stroke: an analysis of data from the Interventional Management of Stroke (IMS III) phase 3 trial. Lancet Neurol 2014;13:567-74 CrossRef Medline

30. Singer OC, Sitzer M, du Mesnil de Rochemont R, et al. Practical limitations of acute stroke MRI due to patient-related problems. Neurology 2004;62:1848-49 CrossRef Medline

31. Nael K, Khan R, Choudhary G, et al. Six-minute magnetic resonance imaging protocol for evaluation of acute ischemic stroke: pushing the boundaries. Stroke 2014;45:1985-91 CrossRef Medline

32. Kidwell CS, Chalela JA, Saver JL, et al. Comparison of MRI and CT for detection of acute intracerebral hemorrhage. JAMA 2004;292: 1823-30 CrossRef Medline

33. Fiebach JB, Schellinger PD, Gass A, et al. Stroke magnetic resonance imaging is accurate in hyperacute intracerebral hemorrhage: a multicenter study on the validity of stroke imaging. Stroke 2004;35: 502-06 CrossRef Medline

34. Jauch EC, Saver JL, Adams HP Jr, et al; American Heart Association Stroke Council, Council on Cardiovascular Nursing, Council on Peripheral Vascular Disease, Council on Clinical Cardiology. Guidelines for the early management of patients with acute ischemic stroke: a guideline for healthcare professionals from the American Heart Association/American Stroke Association. Stroke 2013;44: 870-947 CrossRef Medline

35. Lev MH, Farkas J, Rodriguez VR, et al. CT angiography in the rapid triage of patients with hyperacute stroke to intraarterial thrombolysis: accuracy in the detection of large vessel thrombus. J Comput Assist Tomogr 2001;25:520-28 CrossRef Medline

36. Tomanek AI, Coutts SB, Demchuk AM, et al. MR angiography compared to conventional selective angiography in acute stroke. Can J Neurol Sci 2006;33:58-62 CrossRef Medline

37. Alfke K, Jensen U, Pool C, et al. Contrast-enhanced magnetic resonance angiography in stroke diagnostics: additional information compared with time-of-flight magnetic resonance angiography? Clin Neuroradiol 2011;21:5-10 CrossRef Medline

38. Olivot JM, Mosimann PJ, Labreuche J, et al. Impact of diffusionweighted imaging lesion volume on the success of endovascular reperfusion therapy. Stroke 2013;44:2205-11 CrossRef Medline

39. Yoo AJ, Chaudhry ZA, Nogueira RG, et al. Infarct volume is a pivotal biomarker after intra-arterial stroke therapy. Stroke 2012;43: 1323-30 CrossRef Medline

40. Lansberg MG, Thijs VN, Bammer R, et al; DEFUSE Investigators. Risk factors of symptomatic intracerebral hemorrhage after tPA therapy for acute stroke. Stroke 2007;38:2275-78 CrossRef Medline

41. Schellinger PD, Bryan RN, Caplan LR, et al; Therapeutics and Technology Assessment Subcommittee of the American Academy of Neurology. Evidence-based guideline: the role of diffusion and perfusion MRI for the diagnosis of acute ischemic stroke-report of the Therapeutics and Technology Assessment Subcommittee of the American Academy of Neurology. Neurology 2010;75:177-85 CrossRef Medline

42. Latchaw RE, Alberts MJ, Lev MH, et al; American Heart Association Council on Cardiovascular Radiology and Intervention, Stroke Council, and the Interdisciplinary Council on Peripheral Vascular Disease. Recommendations for imaging of acute ischemic stroke: a scientific statement from the American Heart Association. Stroke 2009;40:3646-78 CrossRef Medline

43. Fiebach JB, Schellinger PD, Jansen O, et al. CT and diffusionweighted MR imaging in randomized order: diffusion-weighted imaging results in higher accuracy and lower interrater variability in the diagnosis of hyperacute ischemic stroke. Stroke 2002;33: 2206-10 CrossRef Medline
44. González RG, Schaefer PW, Buonanno FS, et al. Diffusion-weighted MR imaging: diagnostic accuracy in patients imaged within 6 hours of stroke symptom onset. Radiology 1999;210:155-62 CrossRef Medline

45. Campbell BC, Purushotham A, Christensen S, et al; EPITHETDEFUSE Investigators. The infarct core is well represented by the acute diffusion lesion: sustained reversal is infrequent. J Cereb Blood Flow Metab 2012;32:50-56 CrossRef Medline

46. Wheeler HM, Mlynash M, Inoue $\mathrm{M}$, et al; DEFUSE 2 Investigators. Early diffusion-weighted imaging and perfusion-weighted imaging lesion volumes forecast final infarct size in DEFUSE 2. Stroke 2013; 44:681-85 CrossRef Medline

47. Pulli B, Schaefer PW, Hakimelahi R, et al. Acute ischemic stroke: infarct core estimation on CT angiography source images depends on CT angiography protocol. Radiology 2012;262:593-604 CrossRef Medline

48. Lev MH, Farkas J, Gemmete JJ, et al. Acute stroke: improved nonenhanced CT detection-benefits of soft-copy interpretation by using variable window width and center level settings. Radiology 1999; 213:150-55 CrossRef Medline

49. McTaggart RA, Jovin TG, Lansberg MG, et al; DEFUSE 2 Investigators. Alberta stroke program early computed tomographic scoring performance in a series of patients undergoing computed tomography and MRI: reader agreement, modality agreement, and outcome prediction. Stroke 2015;46:407-12 CrossRef Medline

50. Wisco D, Uchino K, Saqqur M, et al. Addition of hyperacute MRI aids in patient selection, decreasing the use of endovascular stroke therapy. Stroke 2014;45:467-72 CrossRef Medline

51. Fonarow GC, Smith EE, Saver JL, et al. Improving door-to-needle times in acute ischemic stroke: the design and rationale for the American Heart Association/American Stroke Association's Target: Stroke initiative. Stroke 2011;42:2983-89 CrossRef Medline

52. Leifer D, Bravata DM, Connors JJ 3rd, et al; American Heart Association Special Writing Group of the Stroke Council, Atherosclerotic Peripheral Vascular Disease Working Group, Council on Cardiovascular Surgery and Anesthesia, Council on Cardiovascular Nursing. Metrics for measuring quality of care in comprehensive stroke centers: detailed follow-up to Brain Attack Coalition comprehensive stroke center recommendations-a statement for healthcare professionals from the American Heart Association/American Stroke Association. Stroke 2011;42:849-77 CrossRef Medline

53. Mehta BP, Leslie-Mazwi TM, Chandra RV, et al. Reducing door-topuncture times for intra-arterial stroke therapy: a pilot quality improvement project. J Am Heart Assoc 2014;3:e000963 CrossRef Medline

54. Gomez MA 2nd, Hirsch JA, Stingley P, et al. Applying the lean management philosophy to neurointerventional radiology. J Neurointerv Surg 2010;2:83-86 CrossRef Medline

55. Goyal M, Menon BK, Hill MD, et al. Consistently achieving computed tomography to endovascular recanalization $<90$ minutes: solutions and innovations. Stroke 2014;45:e252-56 CrossRef Medline

56. Schellinger PD, Jansen O, Fiebach JB, et al. A standardized MRI stroke protocol: comparison with CT in hyperacute intracerebral hemorrhage. Stroke 1999;30:765-68 CrossRef Medline

57. Ford AL, Williams JA, Spencer M, et al. Reducing door-to-needle times using Toyota's lean manufacturing principles and value stream analysis. Stroke 2012;43:3395-98 CrossRef Medline

58. Wintermark M, Lev MH. FDA investigates the safety of brain perfusion CT. AJNR Am J Neuroradiol 2010;31:2-3 CrossRef Medline

59. Radiation dose in X-ray and CT exams. http:www.radiologyinfo.org/ en/info.cfm?pg = safety-X-ray. Accessed September 6, 2015

60. Corcuera-Solano I, McLellan AM, Doshi AH, et al. Whole-brain adaptive $70-\mathrm{kVp}$ perfusion imaging with variable and extended sampling improves quality and consistency while reducing dose. AJNR Am J Neuroradiol 2014;35:2045-51 CrossRef Medline

61. Shankar JJ, Lum C, Sharma M. Whole-brain perfusion imaging with 320-MDCT scanner: reducing radiation dose by increasing sam- 
pling interval. AJR Am J Roentgenol 2010;195:1183-86 CrossRef Medline

62. Davenport MS, Khalatbari S, Dillman JR, et al. Contrast materialinduced nephrotoxicity and intravenous low-osmolality iodinated contrast material. Radiology 2013;267:94-105 CrossRef Medline

63. Krol AL, Dzialowski I, Roy J, et al. Incidence of radiocontrast nephropathy in patients undergoing acute stroke computed tomography angiography. Stroke 2007;38:2364-66 CrossRef Medline

64. Hopyan JJ, Gladstone DJ, Mallia G, et al. Renal safety of CT angiography and perfusion imaging in the emergency evaluation of acute stroke. AJNR Am J Neuroradiol 2008;29:1826-30 CrossRef Medline

65. Bruce RJ, Djamali A, Shinki K, et al. Background fluctuation of kidney function versus contrast-induced nephrotoxicity. $A J R A m \mathrm{~J}$ Roentgenol 2009;192:711-18 CrossRef Medline

66. Wang Y, Alkasab TK, Narin O, et al. Incidence of nephrogenic systemic fibrosis after adoption of restrictive gadolinium-based contrast agent guidelines. Radiology 2011;260:105-11 CrossRef Medline

67. Fiorella D, Hirsch JA, Woo HH, et al. Should neurointerventional fellowship training be suspended indefinitely? J Neurointerv Surg 2012;4:315-18 CrossRef Medline

68. Hirsch JA, Yoo AJ, Nogueira RG, et al. Case volumes of intra-arterial and intravenous treatment of ischemic stroke in the USA. J Neurointerv Surg 2009;1:27-31 CrossRef Medline

69. Zaidat OO, Lazzaro M, McGinley E, et al. Demand-supply of neurointerventionalists for endovascular ischemic stroke therapy. $\mathrm{Neu}$ rology 2012;79:S35-41 CrossRef Medline

70. Barreto AD, Albright $\mathrm{KC}$, Hallevi $\mathrm{H}$, et al. Thrombus burden is associated with clinical outcome after intra-arterial therapy for acute ischemic stroke. Stroke 2008;39:3231-35 CrossRef Medline

71. Riedel CH, Jensen U, Rohr A, et al. Assessment of thrombus in acute middle cerebral artery occlusion using thin-slice nonenhanced computed tomography reconstructions. Stroke 2010;41:1659-64 CrossRef Medline

72. Riedel CH, Zoubie J, Ulmer S, et al. Thin-slice reconstructions of nonenhanced CT images allow for detection of thrombus in acute stroke. Stroke 2012;43:2319-23 CrossRef Medline

73. Zhu L, Liebeskind DS, Jahan R, et al. Thrombus branching and vessel curvature are important determinants of middle cerebral artery trunk recanalization with Merci thrombectomy devices. Stroke 2012;43:787-92 CrossRef Medline

74. Gupta A, Baradaran H, Schweitzer AD, et al. Carotid plaque MRI and stroke risk: a systematic review and meta-analysis. Stroke 2013;44: 3071-77 CrossRef Medline

75. Wasserman BA, Astor BC, Sharrett AR, et al. MRI measurements of carotid plaque in the Atherosclerosis Risk in Communities (ARIC) study: methods, reliability and descriptive statistics. J Magn Reson Imaging 2010;31:406-15 CrossRef Medline

76. Virani SS, Catellier DJ, Pompeii LA, et al. Relation of cholesterol and lipoprotein parameters with carotid artery plaque characteristics: the Atherosclerosis Risk in Communities (ARIC) carotid MRI study. Atherosclerosis 2011;219:596-602 CrossRef Medline

77. Wasserman BA, Sharrett AR, Lai S, et al. Risk factor associations with the presence of a lipid core in carotid plaque of asymptomatic individuals using high-resolution MRI: the Multi-Ethnic Study of Atherosclerosis (MESA). Stroke 2008;39:329-35 CrossRef Medline

78. Zavodni AE, Wasserman BA, McClelland RL, et al. Carotid artery plaque morphology and composition in relation to incident cardiovascular events: the Multi-Ethnic Study of Atherosclerosis (MESA). Radiology 2014;271:381-89 CrossRef Medline

79. Qiao Y, Steinman DA, Qin Q, et al. Intracranial arterial wall imaging using three-dimensional high isotropic resolution black blood MRI at 3.0 Tesla. J Magn Reson Imaging 2011;34:22-30 CrossRef Medline

80. Qiao Y, Zeiler SR, Mirbagheri S, et al. Intracranial plaque enhancement in patients with cerebrovascular events on high-spatial-resolution MR images. Radiology 2014;271:534-42 CrossRef Medline

81. Qiao Y, Liu L, Zhang Y. Abstract T P108: MRI measurements of intracranial atherosclerosis in the ARIC neurocognitive study: methods, reliability and descriptive statistics. In: International Stroke Conference, Nashville, Tennessee. February 10-12, 2015

82. Mossa-Basha M, Hwang WD, De Havenon A, et al. Multicontrast high-resolution vessel wall magnetic resonance imaging and its value in differentiating intracranial vasculopathic processes. Stroke 2015;46:1567-73 CrossRef Medline

83. Vakil P, Vranic J, Hurley MC, et al. T1 gadolinium enhancement of intracranial atherosclerotic plaques associated with symptomatic ischemic presentations. AJNR Am J Neuroradiol 2013;34:2252-58 CrossRef Medline 